\title{
lodine supplementation: compliance and association with adverse obstetric and neonatal outcomes
}

\author{
Maria Lopes-Pereira1,2,3, Anna Quialheiro1,2, Patrício Costa1,2, Susana Roque1,2, Nadine Correia Santos 1,2,4, \\ Margarida Correia-Neves1,2, Ana Goios 1,2, ${ }^{1}$, Ivone Carvalho5, Tim I M Korevaar6,7,8, Laura Vilarinho5 and \\ Joana Almeida Palha1,2,9 \\ 1 Life and Health Sciences Research Institute (ICVS), School of Medicine, University of Minho, Braga, Portugal \\ 2ICVS/3B's, PT Government Associate Laboratory, Braga/Guimarães, Portugal \\ ${ }_{3}^{3}$ Hospital de Braga, Braga, Portugal \\ 4ACMP5 - Associação Centro de Medicina P5 (P5), School of Medicine, University of Minho, Braga, Portugal \\ ${ }^{5}$ Newborn Screening, Metabolism \& Genetics Unit, National Institute of Health Dr Ricardo Jorge, Porto, Portugal \\ ${ }^{6}$ Academic Center for Thyroid Diseases, Erasmus MC, Rotterdam, the Netherlands \\ ${ }^{7}$ Department of Internal Medicine, Erasmus MC, Rotterdam, the Netherlands \\ ${ }^{8}$ The Generation R Study Group, Erasmus MC, University Medical Center, Rotterdam, the Netherlands \\ ${ }^{9}$ Clinical Academic Center-Braga (2CA-B), Braga, Portugal
}

Correspondence should be addressed to J A Palha: japalha@med.uminho.pt

${ }^{\dagger}$ (A Goios is now at P95 Epidemiology and Pharmacovigilance, Leuven, Belgium)

\begin{abstract}
Objectives: Over 1.9 billion people worldwide are living in areas estimated to be iodine insufficient. Strategies for iodine supplementation include campaigns targeting vulnerable groups, such as women in pre-conception, pregnancy and lactation. Portuguese women of childbearing age and pregnant women were shown to be mildlyto-moderately iodine deficient. As a response, in 2013, the National Health Authority $(\mathrm{NHA})$ issued a recommendation that all women considering pregnancy, pregnant or breastfeeding, take a daily supplement of 150-200 $\mu$ g iodine. This study explored how the iodine supplementation recommendation has been fulfilled among pregnant and lactating women in Portugal, and whether the reported iodine supplements intake impacted on adverse obstetric and neonatal outcomes.

Design and methods: Observational retrospective study on pregnant women who delivered or had a fetal loss in the Braga Hospital and had their pregnancies followed in Family Health Units. Results: The use of iodine supplements increased from $25 \%$ before the recommendation to $81 \%$ after the recommendation. This was mostly due to an increase in the use of supplements containing iodine only. lodine supplementation was protective for the number of adverse obstetric outcomes (odds ratio $(O R)=0.791, P=0.018$ ) and for neonatal morbidities $(\mathrm{OR}=0.528, P=0.024)$ after controlling for relevant confounding variables. Conclusion: The recommendation seems to have succeeded in implementing iodine supplementation during pregnancy. National prospective studies are now needed to evaluate the impact of iodine supplementation on maternal thyroid homeostasis and offspring psychomotor development and on whether the time of the beginning of iodine supplementation (how early during preconception or pregnancy) is relevant to consider.
\end{abstract}




\section{Introduction}

Iodine is an essential nutrient required for the biosynthesis of thyroid hormone. Thyroid hormone regulates growth and metabolism and is essential for proper fetal brainand nervous system development (1). During pregnancy iodine requirements are higher, due to the growing fetus and various physiological adjustments (2), which renders pregnant women more susceptible to iodine insufficiency. Of concern, several studies found an association of iodine insufficiency with increased maternal thyroid volume and structure, adverse pregnancy outcomes, perinatal and infant mortality $(3,4,5,6,7)$, and altered psychomotor development of the newborn, with consequences extended further on during childhood $(8,9)$. Although the deleterious effects of severe iodine deficiency are well recognized, the benefits of interventions correcting mildto-moderate iodine deficiency are uncertain. The latest Cochrane review showed that evidence is still insufficient to conclude on the benefits and harms of iodine supplementation, and that further well-designed studies are necessary (10).

In 2009, we (11) and others (12) showed that Portuguese women of childbearing age and pregnant women had insufficient iodine intake and that pregnant women in the Minho region of Portugal lacked the physiological thyroid hormone adaptations typically observed in otherwise healthy pregnant women from iodine-sufficient populations (13). Moreover, during follow-up, we observed that maternal serum free thyroxine levels in the 1st trimester of pregnancy predicted infant psychomotor development, with altered behavior already detected at 12 months (14). These findings contributed to support a recommendation of the Portuguese National Health Authorities (NHA), in 2013, to provide iodine supplementation (150-200 $\mu \mathrm{g} /$ day) to women during preconception, pregnancy and lactation (15).

Eight years past this recommendation, the present retrospective study was undertaken to explore how the iodine supplementation recommendation has been fulfilled and whether the reported use of iodine supplements was associated with obstetrics and neonatal outcomes.

\section{Materials and methods}

\section{Study design and population}

This observational retrospective study was conducted in Braga (the regional capital of the Minho region in Northern Portugal) in 10 out of 17 family health units
(USF, Unidade de Saúde Familiar, in Portuguese) of the grouping health centers of Cávado I (ACES Cávado I). These 10 USF were selected as those contributing the most to the total number of births in Braga Hospital between 2013 and 2017 (65\%).

The inclusion criteria were pregnant women who delivered or had a fetal loss in the Braga Hospital and had their pregnancies followed up until birth in the selected USFs.

Since the Portuguese National Health Authority (NHA) recommendation on iodine supplementation was published in August 2013, the study sample was analyzed in two groups: (1) before the recommendation group (BR), including those fulfilling the inclusion criteria and who delivered between January and September 2013; and (2) after the recommendation group (AR), including those who fulfilled the inclusion criteria and delivered between July 2014 and December 2017. Births before 2013 were not included due to scarcity of clinical registers.

From the period under study, we collected data from 2860 pregnant women of which 1980 (69\%) fulfilled the inclusion criteria (555 BR and 1425 AR) (Fig. 1).

The manuscript was written respecting the Strengthening the Reporting of Observational Studies in Epidemiology (STROBE) checklist.

\section{Data collection}

Clinical and socioeconomic data regarding background variables and adverse obstetric and neonatal outcomes were retrieved from obstetrics clinical registers from the Department of Obstetrics of Braga's Hospital and from the USF's Maternal Health Consultation. Data collected included age, level of education, parity, previous miscarriages, smoking and alcohol consumption, records of thyroid disease and obesity, height, weight, preconception BMI $\left(\mathrm{kg} / \mathrm{m}^{2}\right)$ and gestational gain weight, reported iron and folic acid supplementation during pregnancy, reported iodine supplementation (since, in most cases, no information was available on the precise start time, iodine supplementation may have started any time during preconception, pregnancy or lactation), gestational age at birth, mode of delivery (caesarean section/vaginal delivery/instrumental delivery), Apgar score and newborn birth weight, length and cephalic perimeter. Newborn TSH levels, between 3rd and 6th day of life, were obtained from the National Neonatal Screening Programme; normal values were considered if $<10 \mathrm{mU} / \mathrm{L}$ (16).

Reported use of iodine supplements was the exposure variable; adverse obstetric outcomes (fetal loss (defined as 


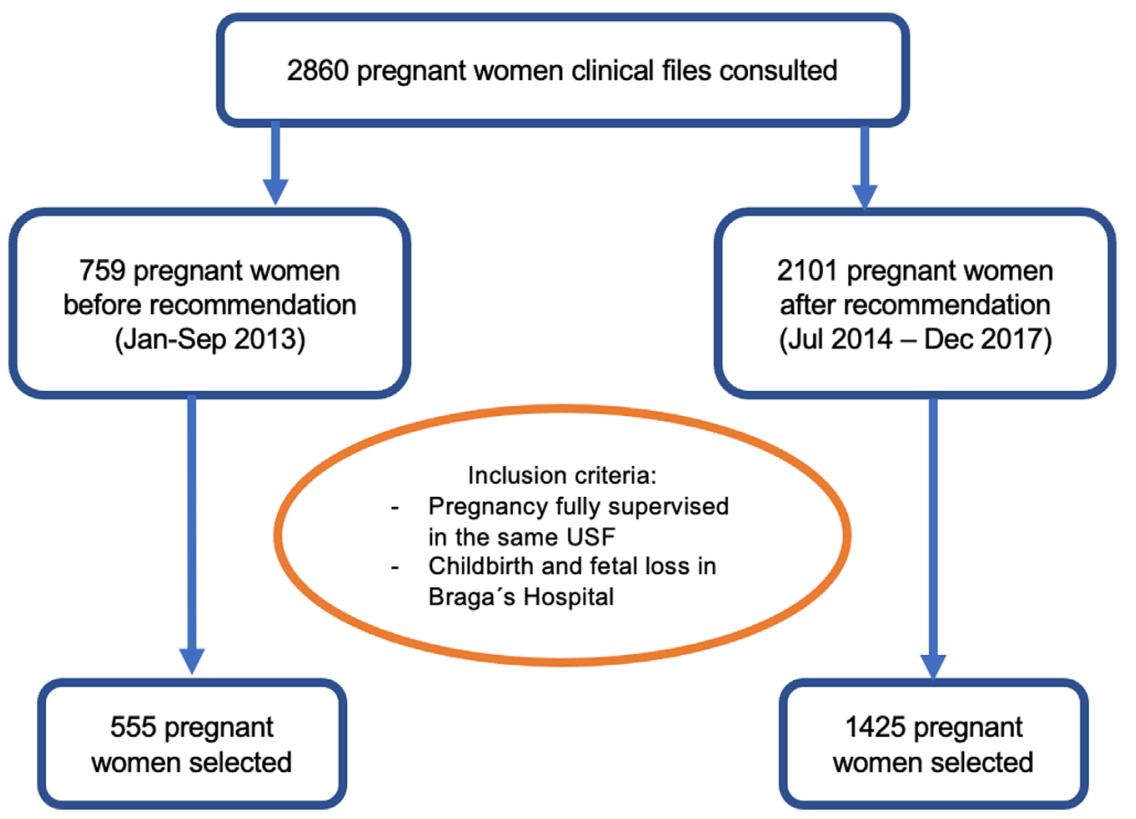

Figure 1

Study flowchart. miscarriage before 20 weeks and stillbirth after 20 weeks), preterm delivery (23-37 weeks), risk of preterm delivery, gestational hypertension and preeclampsia, gestational diabetes, hydramnios, intrauterine growth restriction, placental abruption, small or large for gestational age (defined as birth weight below the 10th and above the 90th percentile, respectively, for gestational age and sex (17)), and congenital malformations) and neonatal morbidities (admission to the neonatal care unit), the main outcome measures.

The following variables were considered as potential confounders: maternal age (increasing maternal age is independently associated with specific adverse pregnancy outcomes (18)), level of education (women with lower levels of education are at greater risk for adverse maternal outcomes (19)), parity (knowing that nulliparity has a higher risk of adverse pregnancy outcomes than low multiparity (20)), previous miscarriages (a previous miscarriage is associated with a higher risk of obstetric complications (21)), smoking (exposure to smoke during pregnancy is associated with an increased risk of obstetric complications and adverse health outcomes for children exposed in utero (22)), alcohol consumption (exposure to alcohol in utero can have numerous adverse effects on a developing fetus (23)), preconception BMI (maternal pre-pregnancy obesity has been associated with higher obstetric outcomes (24)), thyroid disease (overt hypothyroidism and overt hyperthyroidism are reported to increase the risk of miscarriage, preterm delivery and other adverse pregnancy outcomes (25)), and iron and folic supplementation (supplements with iron and folic acid are reported to protect from some neonatal morbidities (26)).

\section{Statistical analysis}

Independence chi-square test was used for qualitative variables and unpaired samples $t$-test or Mann-Whitney test to compare maternal variables and newborn variables, considering intake/no intake of iodine supplementation and also for the comparisons of BR and AR. The tests assumptions were evaluated. For the chi-square test, a maximum of $20 \%$ of expected counts lower than 5 and none less than 1, for 2 by 2 tables Fisher's exact test were reported. Assumption of normality of the distribution was assessed visually through histograms, using the Kolmogorov-Smirnov and ShapiroWilk tests and the skewness and kurtosis measures. For variables with relevant deviations from a normal distribution, the non-parametric correspondent tests were applied, and medians and the interquartile range were reported.

Since women could have more than one adverse obstetric outcomes, Poisson regression was used to predict the number of occurrences. Binary logistic regression was used to predict neonatal morbidities.

For Poisson regression analysis, there was complete information for 1123 women (769 with iodine, 354 without iodine); this population was identical to the original, except for age, in which women with iodine supplementation were 1 year older on average $(P=0.02)$.

For binary logistic regression analysis, there was complete information for 1012 women (728 with iodine, 284 without iodine); this population was identical to the

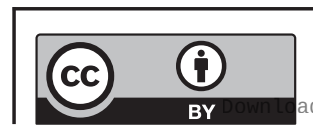

This work is licensed under a Creative Commons Attribution 4.0 International License. 
original in demographic and clinical variables, except for age, in which women with iodine supplementation are 1 year older on average $(P=0.009)$.

While folic acid intake would be a possible confounder for adverse obstetric and neonatal outcomes, it was not considered in the models since all women taking iodine also reported folic acid intake.

Multicollinearity was assessed through the tolerance values for all predictors; the minimum observed value was of 0.516 for education (having a higher education degree).

Statistical analyses were performed using IBM SPSS Statistics (version 25) (IBM Corp.) and results were considered significant when $P<0.05$. Measures of effect sizes were calculated with the correspondent cut-off values: for Pearson's $\phi$, Cramer's V and r, 0.1 small, 0.3 medium and 0.5 large; and for Cohen's $d, 0.2$ small, 0.5 medium and 0.8 large (27).

\section{Results}

The proportion of women reported to use iodine supplements increased from $25 \%$ BR to $81 \%$ AR. The observed increase was mostly due to the use of isolated iodine pills (Fig. 2).

Sociodemographic and clinical information are presented in Table 1. Women in the iodine supplemented group had more years of formal education (small effect size, Pearson's $\phi=0.078$ ). Less women in the iodine supplemented group had thyroid disease (small effect size, Cramer's $V=0.116$ ), smoked (small effect size, Pearson's $\phi=0.069$ ) or consumed alcohol (small effect size, Pearson's $\phi=0.096$ ). More women taking iodine supplements also reported folic acid (medium effect size, Pearson's $\phi=0.344$ ) and iron supplementation (medium effect size, Pearson's $\phi=0.298$ ). Parity, previous miscarriages, preconception BMI, previous obesity and weight gain did not differ among groups.

Table 2 provides information on the adverse obstetric outcomes. Considering all pregnancies, the number of women experiencing adverse obstetric outcomes was higher in the non-iodine supplemented group (small effect size, Pearson's $\phi=0.167$ ), as were the number of miscarriages (small effect size, Pearson's $\phi=0.119$ ). No differences were observed on the adverse obstetric outcomes from viable pregnancies. One hundred thirty-five women had more than one adverse obstetric outcome, with a maximum of 6 .

The analysis can be further explored, considering the time before and after the recommendation (Supplementary Tables 1 and 2, see section on supplementary materials given at the end of this article).

Regression analysis allowed us to control for confounding with respect to the occurrence of adverse obstetric outcomes (Table 3). Intake of iodine and iron were associated with a $25 \%$ (even though not reaching statistical significance, $P=0.055)$ and $87 \%(P<0.001)$ decreased odds, respectively, of having an adverse obstetric outcome. Each year at age of birth and each $\mathrm{kg} / \mathrm{m}^{2}$ of preconception BMI were associated with $5.1 \%(P=0.001)$ and $3.2 \%(P=0.036)$ higher odds of occurrence of an adverse obstetric outcome, respectively.

We next searched for the factors influencing the number of obstetric outcomes (Table 4). Iodine intake was protective, with a $21 \%$ lower odds for the count of adverse obstetric outcomes, as was taking iron supplementation $(52 \%, P<0.001)$ and having had children $(19 \%, P=0.041)$. Age and BMI were positively associated: for every increase in age or in BMI the odds increased 3.3 and $2.3 \%$, respectively, for the count of adverse obstetric outcomes.

Table 5 reports the mode of delivery, newborn characteristics at birth and neonatal morbidities. Taking iodine supplements was associated with lower number of cesarean deliveries (small effect size; Pearson's $\phi=0.065$ ). Even though well within the presently established normal reference range, newborn thyroid-stimulating hormone (TSH) levels were higher in newborns from women with iodine supplementation (small effect size, $r=0.067)$. Neonatal morbidities, birth weight, Apgar index, newborn cephalic perimeter and length, did not differ between groups. Additional comparisons are given in Supplementary Table 3.

Given the number of confounding variables to consider, we next performed the binary regression for neonatal morbidities. Intake of iodine and parity were associated with $47(P=0.024)$ and 57\% $(P=0.011)$ lower odds of having neonatal morbidities, respectively (Table 6 ).

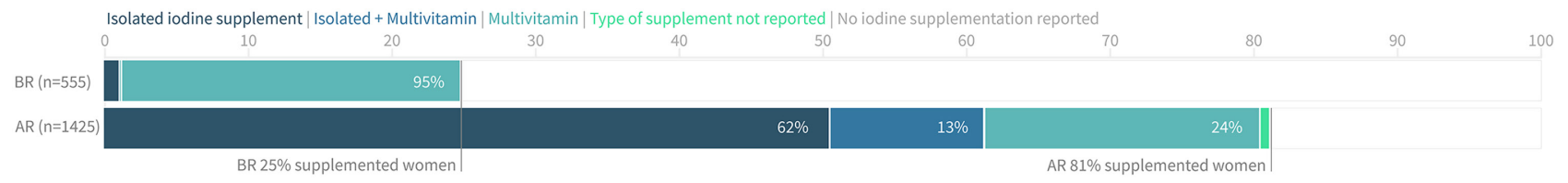

Figure 2

Percentage of women reporting iodine intake and the corresponding intake formula.

https://etj.bioscientifica.com

https://doi.org/10.1530/ETJ-21-0035 (c) 2022 The authors Published by Bioscientifica Ltd.

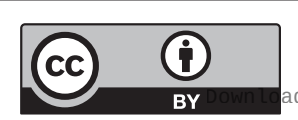

This work is licensed under a Creative Commons Attribution 4.0 International License. ded from Bioscientifica.com at 04/26/2023 11:19:05AM via free access 
Table 1 Participant's characterizationa.

\begin{tabular}{l}
\hline \\
\hline Maternal age (years; mean \pm s.D.) \\
Education (\%) \\
$\quad \leq 9$ years \\
$10-12$ years \\
Certificate after 12 th grade \\
Parity (\%) \\
$\quad$ Nullipara \\
$\quad$ Multiparous $(\geq 1)$ \\
Previous miscarriages (\%) \\
Thyroid disease (\%) \\
Smoking (\%) \\
Alcohol consumption (\%) \\
Folic acid supplementation (\%) \\
Iron supplemmentation (\%) \\
Previous obesity (\%) \\
Preconception BMI (kg/m²; mean \pm s.D.) \\
Weight gain (kg; mean \pm s.D.)
\end{tabular}

\begin{tabular}{c}
\hline No iodine, $\boldsymbol{n}=\mathbf{6 8 7}$ \\
\hline $32 \pm 6$ \\
22 \\
33 \\
45 \\
48 \\
52 \\
21 \\
13 \\
20 \\
12 \\
84 \\
71 \\
13 \\
$24.2 \pm 4.5$ \\
$12.4 \pm 4.8$
\end{tabular}

\begin{tabular}{c}
\hline With iodine, $\boldsymbol{n}=\mathbf{1 2 9 3}$ \\
\hline $32 \pm 5$ \\
19 \\
28 \\
53 \\
52 \\
48 \\
20 \\
6 \\
15 \\
7 \\
100 \\
93 \\
16 \\
$24.1 \pm 4.4$ \\
$12.6 \pm 5.0$
\end{tabular}

\begin{tabular}{r}
\hline P value \\
\hline 0.299 \\
0.007
\end{tabular}

aNo information on: education (for 224 women with iodine supplementation and for 119 women without iodine supplementation), parity (for 4 women with iodine supplementation and for 1 woman without iodine supplementation), previous miscarriages (for 1 woman with iodine supplementation and for 1 woman without iodine supplementation), thyroid disease (for 12 women with iodine supplementation and for 17 women without iodine supplementation), smoking (for 106 women with iodine supplementation and for 84 women without iodine supplementation), alcohol consumption (for 124 women with iodine supplementation and for 85 women without iodine supplementation), folic acid supplementation (for 28 women with iodine supplementation and for 140 women without iodine supplementation), iron supplementation (for 133 women with iodine supplementation and for 193 women without iodine supplementation), previous obesity (for 535 women with iodine supplementation and for 167 women without iodine supplementation), preconception BMI (for 195 women with iodine supplementation and for 142 women without iodine supplementation), weight gain (for 457 women with iodine supplementation and for 343 women without iodine supplementation).

\section{Discussion}

This study shows strong compliance to the recommendation (not mandatory) to supplement women with iodine during preconception, pregnancy and lactation, issued in 2013 by the NHA (15). The proportion of women with reported iodine supplementation increased from $25 \%$ in 2013 to
81\% between 2014 and 2017. Iodine supplementation was mostly from iodine-containing multivitamin formula BR and from potassium iodide (approved by the authorities in March 2012) AR. It is important to mention that a recommendation is not mandatory, and clinicians may decide not to supplement for various reasons. Of notice, monitoring thyroid function is not included in current

Table 2 Adverse obstetric outcomes.

\begin{tabular}{l}
\hline All pregnancies \\
\hline Adverse obstetric outcomes (\%) \\
Miscarriages (\%) \\
Stillbirths (\%) \\
Viable pregnancies \\
\hline Fetal malformations (\%) \\
Gestational diabetes (\%) \\
Gestational hypertension (\%) \\
Hydramnios (\%) \\
Intrauterine growth restriction (\%) \\
Large for gestational age (\%) \\
Placental abruption (\%) \\
Preeclampsia (\%) \\
Preterm delivery (\%) \\
Risk of preterm delivery (\%) \\
Small for gestational age (\%)
\end{tabular}

\begin{tabular}{c} 
No iodine, $\boldsymbol{n}=\mathbf{6 8 7}$ \\
\hline 50 \\
16 \\
0
\end{tabular}

\begin{tabular}{c}
\hline With iodine, $\boldsymbol{n}=\mathbf{1 2 9 3}$ \\
\hline 33 \\
8 \\
0.4
\end{tabular}

P value

$<0.001$

$<0.001$

\begin{tabular}{c} 
No iodine supplementation, $\boldsymbol{n}=\mathbf{4 7 9}$ \\
\hline 2 \\
10 \\
2 \\
0.2 \\
3 \\
3 \\
0 \\
0.6 \\
5 \\
3 \\
13
\end{tabular}

\begin{tabular}{c}
\hline lodine supplementation, $\boldsymbol{n}=\mathbf{1 1 6 2}$ \\
\hline 1 \\
11 \\
2 \\
0.8 \\
4 \\
3 \\
0.4 \\
0.9 \\
4 \\
3 \\
14 \\
\hline
\end{tabular}

$0.171^{a}$

\begin{tabular}{l}
$\boldsymbol{P}$ value \\
0.093 \\
0.490 \\
0.363 \\
$0.298^{a}$ \\
0.408 \\
0.993 \\
$0.330^{a}$ \\
$0.769^{a}$ \\
0.113 \\
0.927 \\
0.378 \\
\hline
\end{tabular}

aFisher's test. Adverse obstetric outcomes (miscarriages, stillbirth, fetal malformations, gestational diabetes, gestational hypertension, hydramnios, intrauterine growth restriction, large for gestational age, placental abruption, preeclampsia, preterm delivery, risk of preterm delivery, small for gestational age). 
Table 3 Binary logistic regression for adverse obstetric outcomes with respect to all pregnancies.

\begin{tabular}{|c|c|c|c|}
\hline Variables & OR & $95 \% \mathrm{Cl}$ & $P$ value \\
\hline Iodine supplementation & 0.748 & $0.557-1.006$ & 0.055 \\
\hline Previous miscarriages & 1.302 & $0.923-1.836$ & 0.133 \\
\hline Maternal age (years) & 1.049 & $1.018-1.080$ & 0.001 \\
\hline High school (10-12 years) & 1.024 & $0.708-1.480$ & 0.901 \\
\hline Certificate after 12 th grade & 0.833 & $0.578-1.201$ & 0.328 \\
\hline Parity ( $\geq 1$ deliveries) & 0.812 & $0.601-1.097$ & 0.174 \\
\hline Smoking & 1.111 & $0.772-1.599$ & 0.569 \\
\hline Alcohol consumption & 1.326 & $0.838-2.098$ & 0.228 \\
\hline Thyroid disease & 0.787 & $0.476-1.302$ & 0.351 \\
\hline Preconception BMI (kg/m²) & 1.032 & $1.002-1.063$ & 0.036 \\
\hline Iron supplementation & 0.128 & $0.082-0.199$ & $<0.001$ \\
\hline
\end{tabular}

Comparators: no iodine supplementation, no miscarriage, $\leq 9$ years of education, no smoking, no previous deliveries, no alcohol consumption, no thyroid disease, no iron supplementation.

OR, odds ratio.

guidelines for pregnancy follow-up, except when thyroid disease is present (28).

Clinical records of iodine supplementation during breastfeedingwerescarce, which may reflectundervaluation by the clinicians that iodine supplementation must continue during lactation.

Of the women taking iodine, 100\% also reported folic acid intake and 93\% also reported the use of iron supplements; while these numbers were only of 84 and $71 \%$, respectively, for those not mentioning iodine supplementation.

In our study, when controlling for the confounding variables, iodine supplementation was associated with lower occurrence of adverse obstetric outcomes and neonatal morbidities. Fewer spontaneous miscarriages were observed in the supplemented group, with an

Table 4 Poisson regression for the number of adverse obstetric outcomes with respect to all pregnancies.

\begin{tabular}{|c|c|c|c|}
\hline Variable & OR & $95 \% \mathrm{Cl}$ & $P$ value \\
\hline lodine supplementation & 0.791 & 0.651 & 0.018 \\
\hline Previous miscarriages & 1.206 & 0.96 & 0.093 \\
\hline Maternal age (years) & 33 & 1.014 & $<0.001$ \\
\hline High school (10-12 years) & 1.004 & $0.786-1.282$ & 0.975 \\
\hline Certificate after 12 th grade & 0.914 & $0.716-1.167$ & 0.470 \\
\hline Parity ( $\geq 1$ deliveries) & 0.812 & 0.66 & 0.041 \\
\hline Smok & 1.134 & 1.430 & 0.286 \\
\hline Alcoh & 8 & 369 & 0.907 \\
\hline disease & 0.881 & 215 & 0.441 \\
\hline Preconception BMI (kg & 1.023 & $1.004-1.043$ & 0.017 \\
\hline Iron supplementation & 0.484 & $0.389-0.603$ & $<0.001$ \\
\hline
\end{tabular}

Comparators: no iodine supplementation, no miscarriage, $\leq 9$ years of education, no smoking, no previous deliveries, no alcohol consumption, no thyroid disease, no iron supplementation. OR, odds ratio. increase $A R$ in both groups, probably due to a more accurate registration in the clinical files over time. This observation adds to the literature, where data is scarce and contradictory. Gowachirapant et al. and Zhou et al. $(29,30)$ suggested that iodine supplementation (200 $\mu \mathrm{g} /$ day) in mildly iodine-deficient pregnant women had no benefit on newborn outcomes. A recent meta-analysis in euthyroid women showed that the pooled prevalence of preterm birth, low birth weight and hypertensive disorders were not associated with first trimester urinary iodine levels (31). Another systematic review and metaanalysis suggested that even though pre-eclamptic women presented lower urinary iodine levels, additional studies are needed to conclude on the association with iodine deficiency (32). Interestingly, in a Norwegian cohort study, iodine supplement use initiated before pregnancy reduced the risk of preeclampsia but not that of other measured adverse outcomes; this study did not address miscarriages (33). In the retrospective study presented here we had no information on urinary iodine or on the timing of iodine supplementation, to further associate the observed findings.

The overall impact of iodine supplementation in improving of maternal health should be viewed with caution within the general guidelines for pregnancy surveillance. The indicators from the Portuguese national low-risk pregnancy surveillance program showed an improvement after 2015 (34), namely, earlier surveillance and more adequate follow-up in pregnancy and puerperium (6 or more consultations), which may be related or independent from the 2013 recommendation on iodine supplementation. Pregnant women compliant with iodine supplementation may be more compliant with the pregnancy surveillance program, further contributing to the reduction in obstetric and neonatal complications.

Another important aspect relates with the dietary habits. This is particularly relevant since increased iodine intake during pregnancy may result from changes in the consumption of iodine-rich foods. In Portugal, despite the liberalization of iodized salt in 1996 and the implementation of measures for the use of iodized salt in school canteens, compliance has been scarce, and the use of dairy products remains the major source of iodine mainly in younger school-age population (silent prophylaxis) (35). Of interest, Japanese food became popular in the country in recent years, which is accompanied by increased consumption of iodine-rich algae. Additional detailed studies on dietary habits are needed to unravel whether food and/or intake of supplements influence the course of pregnancy and its obstetric and neonatal outcomes.

This work is licensed under a Creative Commons Attribution 4.0 International License. 
Table 5 Mode of delivery, newborn characteristics and neonatal morbidities.

\begin{tabular}{l}
\hline Cesarean delivery (\%) \\
Newborn characteristics \\
Apgar index (1 min) $\leq 6$ (\%) \\
Birth weight (g; mean \pm s.D.) \\
Cephalic perimeter (cm) (median; IQR) \\
Length (cm) (median; IQR) \\
TSH (mU/L) (median; IQR) \\
Neonatal morbidities (\%)
\end{tabular}

\begin{tabular}{c}
\hline No iodine, $\boldsymbol{n}=\mathbf{4 7 9} \mathbf{a}$ \\
\hline 35 \\
3 \\
$3175 \pm 505$ \\
$34.5(33.5-35.4)$ \\
$48.5(47.0-50.0)$ \\
$1.185(0.680-1.910)$ \\
8 \\
\hline
\end{tabular}

\begin{tabular}{c}
\hline With iodine, $\boldsymbol{n}=\mathbf{1 1 6 2}^{\mathbf{a}}$ \\
\hline 28 \\
2 \\
$3226 \pm 496$ \\
$34.5(33.5-35.0)$ \\
$48.5(47.0-50.0)$ \\
$1.325(0.800-2.043)$ \\
6 \\
\hline
\end{tabular}

\begin{tabular}{c} 
P value \\
\hline 0.009 \\
0.383 \\
0.067 \\
0.370 \\
0.513 \\
0.007 \\
0.137 \\
\hline
\end{tabular}

aNo information on: type of delivery (for 7 women with no iodine supplementation and for 1 woman with iodine supplementation), Apgar index (1 min) $\leq 6$ (for 12 women with no iodine supplementation and for 9 women with iodine supplementation), birth weight (for 19 women with no iodine supplementation and for 27 women with iodine supplementation), cephalic perimeter (for 82 women with no iodine supplementation and for 66 women with iodine supplementation), length (for 80 women with no iodine supplementation and for 66 women with iodine supplementation), newborn TSH (for 19 women with no iodine supplementation and for 12 women with iodine supplementation).

IQR, interquartile range; TSH, thyroid-stimulating hormone.

We observed that newborn TSH levels were within the normal reference ranges, still higher in the supplemented group, but the effect size was small. This observation warrants that additional longitudinal studies are necessary to infer on the biological significance of such finding and on its relationship with dosage and/or timing of initiation of iodine supplements intake. The incidence of congenital hypothyroidism in Portugal is of 1:2892 newborns and we observed only two cases of suspected congenital hypothyroidism in our sample, both AR (16). An Italian randomized single-blind and placebo-controlled trial with 90 women showed no differences on newborns' TSH levels between the two groups (36). In a recent meta-analysis, most studies showed no effect of iodine supplementation on maternal or infant TSH and free thyroxine serum levels (37). Nazeri et al. in a systematic review of the trials of the last 3 decades, showed no differences in weight, length or head circumference at birth, as we also observed here (38).

Table 6 Binary logistic regression for neonatal morbidities with respect to all viable deliveries.

\begin{tabular}{|c|c|c|c|}
\hline Variables & OR & $95 \% \mathrm{Cl}$ & $P$ value \\
\hline Iodine supplementation & 0.528 & $0.303-0.920$ & 0.024 \\
\hline Previous miscarriages & 0.865 & & \\
\hline Maternal age (years) & 1.031 & $0.972-1.095$ & 0.309 \\
\hline High school (10-12 years) & 1.228 & $0.565-2.669$ & 0.605 \\
\hline Certificate after 12 th grade & 1.021 & $0.469-2.223$ & 0.958 \\
\hline ( $\geq 1$ deliveries) & 0.430 & 0.225 & 0.011 \\
\hline Smo & 1.2 & 0.624 & 0.518 \\
\hline Alcohol consump & 0.940 & $0.357-2.479$ & 0.901 \\
\hline Thyroid disease & 1.202 & $0.486-2.977$ & 0.690 \\
\hline Precc & 1.003 & $0.943-1.068$ & 0.917 \\
\hline Iron supplementation & 0.802 & $0.235-2.731$ & 0.724 \\
\hline
\end{tabular}

Comparators: no iodine supplementation, no miscarriage, $\leq 9$ years of education, no smoking, no previous deliveries, no alcohol consumption, no thyroid disease, no iron supplementation.

$\mathrm{OR}$, odds ratio.

https://etj.bioscientifica.com

https://doi.org/10.1530/ETJ-21-0035

(c) 2022 The authors Published by Bioscientifica Ltd.
A final note on the comparison of the groups BR and AR. Women on iodine supplementation seem more compliant with pregnancy surveillance and recommendations, irrespectively of time.

There are meaningful limitations of this study. First, this is a retrospective observational study, so no causal relations can be established. Reporting bias is the main limitation. This may be particularly relevant before 2013 with respect to the registration of use of multivitamin supplements. If more women took iodine-containing vitamins without reporting and were, as such, included in the non-supplemented group, this may have diluted the observed effects. Also, information on the use of iodine supplements does not necessarily mean compliance. If less women then registered did comply with the recommendation, the observed differences may as well be lower than the reality. In both situations, the reported associations between iodine intake and adverse obstetric outcomes may be even higher than the observed.

Iodine supplementation is not necessarily synonymous of iodine sufficiency. We have no information about urinary iodine concentration, serum thyroid hormone levels or dietary iodine consumption for most of the women in the present study. Of interest, a recent study in the Portuguese São Miguel Azorean Island showed that the proportion of pregnant women with insufficient urinary iodine decreased from $99 \%$ BR to $91 \%$ AR. Despite of the amelioration, the data suggest that compliance with the iodine supplement intake is low (39).

Most clinical records did not include the precise timing of iodine supplementation, which may impact on the obstetric and neonatal outcomes. Additional studies are needed to understand whether and how the start time of iodine supplementation, and the women's iodine

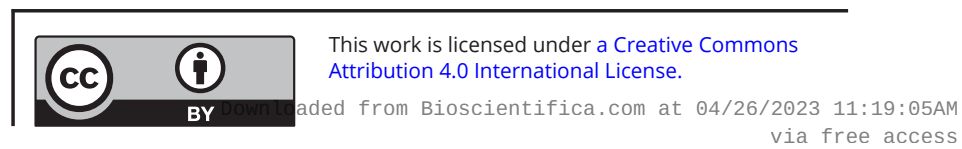


nutritional status influence obstetric, neonatal and child development outcomes (40).

\section{Supplementary materials}

This is linked to the online version of the paper at https://doi.org/10.1530/ ETJ-21-0035.

\section{Declaration of interest}

The authors declare that there is no conflict of interest that could be perceived as prejudicing the impartiality of the research reported. T I M K has received lectureship fees from Merck, Goodlife Healthcare, Berlin Chemie and Quidell.

\section{Funding}

This work has been funded by National funds, through the Foundation for Science and Technology (FCT) - project UIDB/50026/2020 and UIDP/50026/2020 and by the project NORTE-01-0145-FEDER-000039, supported by Norte Portugal Regional Operational Programme (NORTE 2020), under the PORTUGAL 2020 Partnership Agreement, through the European Regional Development Fund (ERDF). Funding agencies did not participate in any part of the research or in data or manuscript preparation.

\section{Statement of ethics}

The study was authorized by national (National Data Protection Commission (authorization No. 11200/2017), regional (ACES Cávado I, Regional Health Administration of the North Committee on Health Ethics, Opinion no. 65/2018) and local (Braga's Hospital Ethics Committee Ref. $16 / 2018$ ) authorities and required no written informed consent.

\section{Data availability statement}

The datasets used and/or analyzed during the current study will be available from the corresponding author on reasonable request.

\section{Author contribution statement}

$M L P, J A P, L V, M C N, P C, S R$ and TI M K contributed to the study design. $N C S$, J A P and M L P prepared the documentation for all ethical approvals. $M L P, I C, A$ Q, A G and S R collected data. M L P, J A P and P C analyzed the data that was discussed with all authors. A G and $S R$ prepared the figures. M L P and J A P wrote the first draft of the manuscript which was critically reviewed and approved in its final format by all authors. All the authors approved the final version to be published and agreed to be accountable for all aspects of the work in ensuring that questions related to the accuracy or integrity of any part of the work are appropriately investigated and resolved.

\section{References}

1 Salazar P, Cisternas P, Martinez M \& Inestrosa NC. Hypothyroidism and cognitive disorders during development and adulthood: implications in the central nervous system. Molecular Neurobiology 201956 2952-2963. (https://doi.org/10.1007/s12035-018-1270-y)

2 Glinoer D. The importance of iodine nutrition during pregnancy. Public Health Nutrition 200710 1542-1546. (https://doi.org/10.1017/ S1368980007360886)

3 Delong GR, Leslie PW, Wang SH, Jiang XM, Zhang ML, Rakeman M, Jiang JY, Ma T \& Cao XY. Effect on infant mortality of iodination of irrigation water in a severely iodine-deficient area of China. Lancet 1997350 771-773. (https://doi.org/10.1016/s0140-6736(96)12365-5)

4 Mannisto T, Mendola P, Grewal J, Xie Y, Chen Z \& Laughon SK. Thyroid diseases and adverse pregnancy outcomes in a contemporary US cohort. Journal of Clinical Endocrinology and Metabolism 201398 2725-2733. (https://doi.org/10.1210/jc.20124233)

5 Pharoah PO, Buttfield IH \& Hetzel BS. Neurological damage to the fetus resulting from severe iodine deficiency during pregnancy. Lancet 19711 308-310. (https://doi.org/10.1016/s0140-6736(71)91040-3)

6 Kung AW, Chau MT, Lao TT, Tam SC \& Low LC. The effect of pregnancy on thyroid nodule formation. Journal of Clinical Endocrinology and Metabolism 200287 1010-1014. (https://doi. org/10.1210/jcem.87.3.8285)

7 Rotondi M, Amato G, Biondi B, Mazziotti G, Del Buono A, Rotonda Nicchio M, Balzano S, Bellastella A, Glinoer D \& Carella C. Parity as a thyroid size-determining factor in areas with moderate iodine deficiency. Journal of Clinical Endocrinology and Metabolism $2000 \mathbf{8 5}$ 4534-4537. (https://doi.org/10.1210/jcem.85.12.7002)

8 Bath SC, Steer CD, Golding J, Emmett P \& Rayman MP. Effect of inadequate iodine status in UK pregnant women on cognitive outcomes in their children: results from the Avon Longitudinal Study of Parents and Children (ALSPAC). Lancet 2013382 331-337. (https:// doi.org/10.1016/S0140-6736(13)60436-5)

9 Zimmermann MB. Iodine deficiency. Endocrine Reviews 200930 376-408. (https://doi.org/10.1210/er.2009-0011)

10 Harding KB, Pena-Rosas JP, Webster AC, Yap CM, Payne BA, Ota E $\&$ De-Regil LM. Iodine supplementation for women during the preconception, pregnancy and postpartum period. Cochrane Database of Systematic Reviews 20173 CD011761. (https://doi. org/10.1002/14651858.CD011761.pub2)

11 Costeira MJ, Oliveira P, Ares S, De Escobar GM \& Palha JA. Iodine status of pregnant women and their progeny in the Minho Region of Portugal. Thyroid 200919 157-163. (https://doi.org/10.1089/ thy.2008.0249)

12 Limbert E, Prazeres S, Sao Pedro M, Madureira D, Miranda A, Ribeiro M, Jacome De Castro J, Carrilho F, Oliveira MJ, Reguengo H, et al. Iodine intake in Portuguese pregnant women: results of a countrywide study. European Journal of Endocrinology 2010163 631-635. (https://doi.org/10.1530/EJE-10-0449)

13 Costeira MJ, Oliveira P, Ares S, Roque S, De Escobar GM \& Palha JA. Parameters of thyroid function throughout and after pregnancy in an iodine-deficient population. Thyroid 201020 995-1001. (https://doi. org/10.1089/thy.2009.0356)

14 Costeira MJ, Oliveira P, Santos NC, Ares S, Saenz-Rico B, De Escobar GM \& Palha JA. Psychomotor development of children from an iodine-deficient region. Journal of Pediatrics 2011159 447-453. (https://doi.org/10.1016/j.jpeds.2011.02.034)

15 DGS. Aporte de iodo em mulheres na preconceção, gravidez e amamentação. Circular Normativa 011/2013. Lisbon, Portugal: Direção Geral de Saúde, 2013. (available at: https://alimentacaosaudavel.dgs.pt/ activeapp2020/wp-content/uploads/2020/01/Aporte-de-iodoem-mulheres-na-precocenc\%CC\%A7a\%CC\%83o-gravidez-eamamentac\%CC\%A7a\%CC\%83o.pdf)

16 Vilarinho L, Garcia P, Pinho e Costa P \& Comissão Executiva do Programa Nacional de Diagnóstico Precoce. Programa Nacional de Diagnóstico Precoce: Relatório 2018. Lisbon, Portugal: Instituto Nacional de Saúde Doutor Ricardo Jorge, IP, 2019. (available at: http://hdl. handle.net/10400.18/6397)

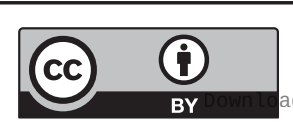

This work is licensed under a Creative Commons Attribution 4.0 International License. 
17 Fenton TR \& Kim JH. A systematic review and meta-analysis to revise the Fenton growth chart for preterm infants. BMC Pediatrics 201313 59. (https://doi.org/10.1186/1471-2431-13-59)

18 Cleary-Goldman J, Malone FD, Vidaver J, Ball RH, Nyberg DA, Comstock CH, Saade GR, Eddleman KA, Klugman S, Dugoff L, et al. Impact of maternal age on obstetric outcome. Obstetrics and Gynecology 2005105 983-990. (https://doi.org/10.1097/01. AOG.0000158118.75532.51)

19 Tuncalp O, Souza JP, Hindin MJ, Santos CA, Oliveira TH, Vogel JP, Togoobaatar G, Ha DQ, Say L, Gulmezoglu AM, et al. Education and severe maternal outcomes in developing countries: a multicountry cross-sectional survey. BJOG 2014121 (Supplement 1) 57-65. (https:// doi.org/10.1111/1471-0528.12634)

20 Bai J, Wong FW, Bauman A \& Mohsin M. Parity and pregnancy outcomes. American Journal of Obstetrics and Gynecology 2002186 274-278. (https://doi.org/10.1067/mob.2002.119639)

21 Bhattacharya S, Townend J, Shetty A, Campbell D \& Bhattacharya S. Does miscarriage in an initial pregnancy lead to adverse obstetric and perinatal outcomes in the next continuing pregnancy? BJOG 2008 115 1623-1629. (https://doi.org/10.1111/j.1471-0528.2008.01943.x)

22 Rogers JM. Tobacco and pregnancy. Reproductive Toxicology 200928 152-160. (https://doi.org/10.1016/j.reprotox.2009.03.012)

23 Hannigan JH \& Armant DR. Alcohol in pregnancy and neonatal outcome. Seminars in Neonatology 20005 243-254. (https://doi. $\operatorname{org} / 10.1053 /$ siny.2000.0027)

24 Papachatzi E, Dimitriou G, Dimitropoulos K \& Vantarakis A. Prepregnancy obesity: maternal, neonatal and childhood outcomes. Journal of Neonatal-Perinatal Medicine 20136 203-216. (https://doi org/10.3233/NPM-1370313)

25 Nazarpour S, Ramezani Tehrani F, Simbar M \& Azizi F. Thyroid dysfunction and pregnancy outcomes. Iranian Journal of Reproductive Medicine 201513 387-396. (available at: https://www.ncbi.nlm.nih. gov/pmc/articles/PMC4609317/pdf/ijrm-13-387.pdf)

26 Haider BA \& Bhutta ZA. Multiple-micronutrient supplementation for women during pregnancy. Cochrane Database of Systematic Reviews 2017 4 CD004905. (https://doi.org/10.1002/14651858.CD004905.pub5)

27 Cohen J. Statistical Power Analysis for the Behavioral Sciences. New York, NY, USA: Routledge Academic, 1988. (https://doi. org/10.4324/9780203771587)

28 DGS. Prescrição de Exames Laboratoriais para Avaliação e Monitorização da Função Tiroideia. Norma 039/2011. Lisbon, Portugal: Direcção Geral da Saúde, 2011. (available at: https://nocs.pt/funcao-tiroideia/)

29 Gowachirapant S. Effects of iodine supplementation in mild to moderately iodine-deficient pregnant women on thyroid function, pregnancy outcomes and newborn development in Thailand. Doctoral Dissertation. Wageningen University, Wageningen, the Netherlands, 2014. (available at: https://edepot.wur.nl/306954)

30 Zhou SJ, Skeaff SA, Ryan P, Doyle LW, Anderson PJ, Kornman L, Mcphee AJ, Yelland LN \& Makrides M. The effect of iodine supplementation in pregnancy on early childhood neurodevelopment and clinical outcomes: results of an aborted randomised placebocontrolled trial. Trials 201516 563. (https://doi.org/10.1186/s13063015-1080-8)
31 Nazarpour S, Ramezani Tehrani F, Behboudi-Gandevani S, Bidhendi Yarandi R \& Azizi F. Maternal urinary iodine concentration and pregnancy outcomes in euthyroid pregnant women: a systematic review and meta-analysis. Biological Trace Element Research 2020197 411-420. (https://doi.org/10.1007/s12011-019-02020-x)

32 Businge CB, Usenbo A, Longo-Mbenza B \& Kengne AP. Insufficient iodine nutrition status and the risk of pre-eclampsia: a systemic review and meta-analysis. BMJ Open 202111 e043505. (https://doi. org/10.1136/bmjopen-2020-043505)

33 Abel MH, Caspersen IH, Sengpiel V, Jacobsson B, Meltzer HM, Magnus P, Alexander J \& Brantsaeter AL. Insufficient maternal iodine intake is associated with subfecundity, reduced foetal growth, and adverse pregnancy outcomes in the Norwegian mother, father and child cohort study. BMC Medicine 202018 211. (https://doi. org/10.1186/s12916-020-01676-w)

34 DGS. Programa Nacional para a Vigilância da Gravidez de Baixo Risco. Lisbon, Portugal: Direção Geral da Saúde, 2015. (available at: https:// www.dgs.pt/em-destaque/programa-nacional-para-a-vigilancia-dagravidez-de-baixo-risco-pdf11.aspx)

35 Costa Leite J, Keating E, Pestana D, Cruz Fernandes V, Maia ML, Norberto S, Pinto E, Moreira-Rosario A, Sintra D, Moreira B, et al. Iodine status and iodised salt consumption in portuguese school-aged children: the iogeneration study. Nutrients 20179 458. (https://doi. org/10.3390/nu9050458)

36 Censi S, Watutantrige-Fernando S, Groccia G, Manso J, Plebani M, Faggian D, Mion MM, Venturini R, Andrisani A, Casaro A, et al. The effects of iodine supplementation in pregnancy on iodine status, thyroglobulin levels and thyroid function parameters: results from a randomized controlled clinical trial in a mild-to-moderate iodine deficiency area. Nutrients 201911 2639. (https://doi.org/10.3390/ nu11112639)

37 Dineva M, Fishpool H, Rayman MP, Mendis J \& Bath SC. Systematic review and meta-analysis of the effects of iodine supplementation on thyroid function and child neurodevelopment in mildly-to-moderately iodine-deficient pregnant women. American Journal of Clinical Nutrition 2020112 389-412. (https://doi.org/10.1093/ajcn/nqaa071)

38 Nazeri P, Shariat M \& Azizi F. Effects of iodine supplementation during pregnancy on pregnant women and their offspring: a systematic review and meta-analysis of trials over the past 3 decades. European Journal of Endocrinology 2021184 91-106. (https://doi.org/10.1530/EJE20-0927)

39 Sousa I, SA, Carvalho R, Mendes I, Prazeres S, César R \& Limbert E. Carência de iodo nas grávidas da Ilha de São Miguel, Açores: avaliação do impacto das medidas corretivas. Revista Portuguesa de Endocrinologia, Diabetes e Metabolismo 202015 142-145. (https://doi. org/10.1016/S1646-3439(12)70002-0)

40 Lopes-Pereira M, Roque S, Costa P, Quialheiro A, Santos NC, Goios A, Vilarinho L, Correia-Neves M \& Palha JA. Impact of iodine supplementation during preconception, pregnancy and lactation on maternal thyroid homeostasis and offspring psychomotor development: protocol of the IodineMinho prospective study. BMC Pregnancy and Childbirth 202020 693. (https://doi.org/10.1186/ s12884-020-03376-y)

Received in final form 3 September 2021

Accepted 16 September 2021

Accepted Manuscript published online 17 September 2021 https://etj.bioscientifica.com https://doi.org/10.1530/ETJ-21-0035 (c) 2022 The authors Published by Bioscientifica Ltd.

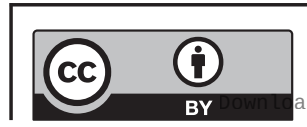

This work is licensed under a Creative Commons Attribution 4.0 International License.

ded from Bioscientifica.com at 04/26/2023 11:19:05AM 